\title{
Electrochemically Deposited Polypyrrole for Dye-Sensitized Solar Cell Counter Electrodes
}

\author{
Khamsone Keothongkham, ${ }^{1}$ Samuk Pimanpang, ${ }^{1}$ Wasan Maiaugree, ${ }^{1}$ \\ Saman Saekow, ${ }^{1}$ Wirat Jarernboon, ${ }^{2}$ and Vittaya Amornkitbamrung ${ }^{1}$ \\ ${ }^{1}$ Department of Physics, Faculty of Science, Khon Kaen University, Khon Kaen 40002, Thailand \\ ${ }^{2}$ College of Nanotechnology, King Mongkut's Institute of Technology Ladkrabang, Chalongkrung Road, \\ Ladkrabang, Bangkok 10520, Thailand
}

Correspondence should be addressed to Samuk Pimanpang, samukpi@kku.ac.th

Received 1 July 2011; Accepted 6 October 2011

Academic Editor: Shahed Khan

Copyright (C) 2012 Khamsone Keothongkham et al. This is an open access article distributed under the Creative Commons Attribution License, which permits unrestricted use, distribution, and reproduction in any medium, provided the original work is properly cited.

\begin{abstract}
Polypyrrole films were coated on conductive glass by electrochemical deposition (alternative current or direct current process). They were then used as the dye-sensitized solar cell counter electrodes. Scanning electron microscopy revealed that polypyrrole forms a nanoparticle-like structure on the conductive glass. The amount of deposited polypyrrole (or film thickness) increased with the deposition duration, and the performance of polypyrrole based-dye-sensitized solar cells is dependant upon polymer thickness. The highest efficiency of alternative current and direct current polypyrrole based-dye-sensitized solar cells (DSSCs) is $4.72 \%$ and $4.02 \%$, respectively. Electrochemical impedance spectroscopy suggests that the superior performance of alternative current polypyrrole solar cells is due to their lower charge-transfer resistance between counter electrode and electrolyte. The large charge-transfer resistance of direct current solar cells is attributed to the formation of unbounded polypyrrole chains minimizing the $\mathrm{I}_{3}{ }^{-}$reduction rate.
\end{abstract}

\section{Introduction}

Dye-sensitized solar cells (DSSCs) have attracted worldwide attention because of their low fabrication costs, promising light harvesting to energy conversion efficiency, and environmental friendliness. The high energy conversion efficiency, of dyesensitized solar cells is accomplished through the use of highly porous semiconductor films coated with dyesensitizer as the working electrode. This was developed by O’Regan and Grätzel in 1991 [1]. Dye-sensitized solar cells consist of three main components: working electrode, electrolyte, and counter electrode. The working electrode is usually $\mathrm{TiO}_{2}$ coated with dye to absorb light and generate electrons. The electrolyte is a mixture of $\mathrm{I}^{-} / \mathrm{I}_{3}{ }^{-}$for transferring electrons from counter electrode to excited dyes. The counter electrode is coated with a catalyst film to promote electron transfer to the electrolyte through the reduction of tri-iodide $\left(\mathrm{I}_{3}{ }^{-}\right)$[2-4]. Nishikitani et al. [5] found that DSSC short-current density $\left(J_{\text {sc }}\right)$ is dependant on $\mathrm{I}^{-}$concentration, $\left[\mathrm{I}^{-}\right]$, as follows:

$$
J_{\mathrm{sc}}=\frac{k_{d}\left[\mathrm{I}^{-}\right]}{k_{b}\left[n_{0}\right]+k_{d}\left[\mathrm{I}^{-}\right]} q \varphi A \phi
$$

where $k_{b}$ and $k_{d}$ are the rate constants for back and forward electron transfer reactions, respectively. $\left[n_{0}\right]$ is the electron density in $\mathrm{TiO}_{2}$ in the dark, $q$ is the electron charge, $\varphi$ is the electron injection efficiency, $\phi$ is the incident photon flux, and $A$ is the ratio of absorbed photon flux to $\phi$. Thus, increasing $\mathrm{I}^{-}$concentration in solar-cell systems boosts both the solar-cell current density and the solar-cell performance. Pt thin films are the preferred counter electrode because they have the highest catalytic activity with the $\mathrm{I}_{3}{ }^{-}$. However, due to their high cost, alternative materials are intensively studied such as carbon black [6], carbon nanotube [7], and conductive polymers $[8,9]$. 
Conducting polymers are promising candidates for DSSC counter electrodes because of their unique properties, including low cost, good conductivity, remarkable stability, and good catalytic activity for $\mathrm{I}_{3}{ }^{-}$reduction [10-13]. Many conductive polymers (polypyrrole, polyaniline, and poly (3,4ethylenedioxythiophene), polythiophene) were investigated as materials for DSSC counter electrodes. Polypyrrole (PPy) is one of the most studied polymers because of its high conductivity and good electrochemical properties $[14,15]$. It is widely used in various applications such as supercapacitors [16-18], field emission [19], sensors [20, 21], and dyesensitized solar cells [22-24]. Wu et al. [22] constructed polypyrrole nanoparticles by chemical polymerization and then affixed this polymer material to conductive glass, where it was used as DSSC counter electrodes. They obtained high energy conversion efficiency $\sim 7.66 \%$. Jeon et al. [23] fabricated polypyrrole nanosphere by chemical polymerization and used these materials as DSSC counter electrodes. This study obtained high DSSC efficiency $\sim 7.73 \%$. This high solar cell performance is most likely due to an increase in counter electrode interfacial area. The result is a rapid $\mathrm{I}_{3}{ }^{-}$reduction rate, that is, large $\mathrm{I}^{-}$concentrations, and large $J_{\mathrm{sc}}$ values as predicted by (1).

Makris et al. [24] placed polypyrrole film on conductive glass by electrochemical deposition and used this as counter electrodes of a quasi solid-state DSSC. They obtained promising results with the highest efficiency $\sim 4.6 \%$. Direct polymer deposition on conductive glass should favor strong polymer bonding to conductive surfaces. This will facilitate electron transport from the conductive glass to polymer and improve DSSC performance. In this present work, we report the preparation of PPy films by two electrochemical deposition processes, alternating current $(\mathrm{AC})$ and direct current (DC), at various deposition durations. The performance of AC and DC DSSCs was analyzed and compared to the performance of Pt DSSCs. The influence upon solar cell performance was analyzed by electrochemical impedance spectroscopy and cyclic voltammetry. The polymer structure was characterized by scanning electron microscopy.

\section{Experimental}

2.1. Polypyrrole (PPy) Films. A fluoride-doped tin oxide (FTO, sheet resistance $8 \Omega / \mathrm{sq}$, Solaronix, SA) glass was used as the conducting substrate for both working and counter electrodes. Conductive glass was masked with tape leaving an open area of $0.4 \mathrm{~cm} \times 1.1 \mathrm{~cm}$ for specific polymerization. Pyrrole solution, a mixture of $100 \mu \mathrm{L}$ pyrrole monomer in $20 \mathrm{~mL}$ of $0.5 \mathrm{M}$ sulfuric acid $\left(\mathrm{H}_{2} \mathrm{SO}_{4}\right)$, was used for depositing polymer films. Alternating current (AC) deposition was conducted in a three-electrode cell: a Pt plate as a counter electrode, an $\mathrm{Ag} / \mathrm{AgCl}$ electrode as a reference electrode, and FTO glass as a working electrode at potential ranged from 0 $\mathrm{V}$ to $0.8 \mathrm{~V}$ and a scan rate of $50 \mathrm{mV} / \mathrm{s}$. Three deposition cycles $(1,2$, and 3$)$ were used for coating conductive glass with PPy films. In case of direct current (DC) deposition, Pt plate and FTO glass were used as the counter electrode and the working electrode, respectively, at electrical potential $0.8 \mathrm{~V}$ for two deposition durations ( $4 \mathrm{~s}$ and $8 \mathrm{~s}$ ). PPy films were rinsed with distilled water and then by ethanol several times to remove sulfuric acid and water residuals. Pt thermally deposited films were prepared via a spin coating of Pt solution. This solution was composed of $20 \mathrm{mM}$ tetraammine platinum (II) chloride hydrate $\left(\mathrm{Pt}\left(\mathrm{NH}_{3}\right)_{4} \mathrm{Cl}_{2} \cdot \mathrm{H}_{2} \mathrm{O}\right), 0.2 \mathrm{~g}$ ethyl cellulose in $5 \mathrm{~mL}$ distilled water, and $15 \mathrm{~mL}$ isopropanol. It was then annealed at $500^{\circ} \mathrm{C}$ for $1 \mathrm{~h}$.

2.2. $\mathrm{TiO}_{2}$ Films. The porous $\mathrm{TiO}_{2}$ film was prepared by a screen printing method. Briefly, the blocking layer was applied to conducting glass by dipping glass pieces in $40 \mathrm{mM}$ titanium tetrachloride $\left(\mathrm{TiCl}_{4}\right)$ solution at $70^{\circ} \mathrm{C}$ for $30 \mathrm{~min}$. The blocking layer was coated with transparent and scattering $\mathrm{TiO}_{2}$ films using commercial $\mathrm{TiO}_{2}$ pastes. The compounds used were PST-18NR and PST-400C (JGC Catalysts and Chemicals Company, Japan) as transparent and scattering layers, respectively. $\mathrm{TiO}_{2}$ films were dried at $80^{\circ} \mathrm{C}$ for $10 \mathrm{~min}$ and then sintered at an ambient air temperature $500^{\circ} \mathrm{C}$ for $1 \mathrm{~h}$. The $\mathrm{TiO}_{2}$ thickness was $\sim 10 \mu \mathrm{m}$ as observed by cross-section scanning electron microscopy. $\mathrm{TiO}_{2}$ film was treated by UV light exposure for 10 min Treated $\mathrm{TiO}_{2}$ film was immersed in $0.3 \mathrm{mM}$ cis-bis-(isothiocyanato)bis(2,2-bipyridyl-4,4-dicarboxylato)-ruthenium(II)-bistetrabutylammonium (N-719, Solaronix) in acetonitrile/tert-butanol $(1: 1 \mathrm{v} / \mathrm{v})$ solution under dark conditions for $24 \mathrm{~h}$ at room temperature. Dye residuals were removed by washing in ethanol.

2.3. Cell Assembly. A sandwich type DSSCs were assembled by using dye-coated $\mathrm{TiO}_{2}$ film as the working electrodes and PPy or Pt films as the counter electrodes. The electrodes were bonded together with a plastic film (Surlyn, thickness $\sim 60 \mu \mathrm{m})$. The electrolyte, a mixture of $0.05 \mathrm{M}$ iodine $\left(\mathrm{I}_{2}\right)$, $0.10 \mathrm{M}$ lithium iodide (LiI), $0.0025 \mathrm{M}$ lithium carbonate $\left(\mathrm{Li}_{2} \mathrm{CO}_{3}\right), 0.50 \mathrm{M}$ of 4 -tert-butylpyridine (TBP), and $0.60 \mathrm{M}$ of 1-methyl-3-propylimidazolium iodide (MPI) in acetonitrile, was injected into a drilled hole on the counter electrode. Then, the drilled hole was sealed with plastic covered with a piece of a glass slide.

2.4. Film and Cell Characteristics. The dye-sensitized solar cell characteristics were analyzed using a solar simulator (PEC-L11, Japan) under air mass 1.5 and light intensity of $100 \mathrm{~mW} / \mathrm{cm}^{2}$. The DSSC impedance was measured by electrochemical impedance spectroscopy (Gamry REF 3000, USA) under a light intensity $100 \mathrm{~mW} / \mathrm{cm}^{2}$, frequency ranging from $0.01 \mathrm{~Hz}$ to $100,000 \mathrm{~Hz}$ and an $\mathrm{AC}$ amplitude of $100 \mathrm{mV}$. Catalytic activities of PPy and Pt films were analyzed by cyclic voltammetry with a three-component electrode: Pt plate as the counter electrode, $\mathrm{Ag} / \mathrm{AgCl}$ electrode as the reference electrode, and $\mathrm{PPy}$ or Pt films as the working electrode at a scan rate of $20 \mathrm{mV} / \mathrm{s}$. The film surface morphology and thickness were characterized by scanning electron microscopy (SEM, 1450VP. LEO Company, England). Polymer thickness was measured by VEECO Dektak 150 Surface Profiler. 


\section{Results and Discussion}

3.1. PPy Films. Polypyrrole films prepared using alternating current (AC) at a scanning rate of $20 \mathrm{mV} / \mathrm{s}$ exhibited the deposited current as shown in Figure 1(a). It was seen that the first deposit cycle had very low current below $0.6 \mathrm{~V}$. However, above $0.6 \mathrm{~V}$, the current increases significantly. This means that polymer starts depositing on the conductive glass at about $0.6 \mathrm{~V}$. In the second and third deposition cycles, polymer forms on the substrate at voltages greater than $\sim 0.4 \mathrm{~V}$. The reduction of the deposit voltage in the second and third cycles implies easier polymerization. This voltage reduction is possibly due to monomer being more easily polymerized onto existed PPy sites than onto the FTO surfaces. PPy formation onto the glass is proposed to occur as illustrated in Figure 2(a). A similar phenomenon was observed in electrochemical deposition of polyaniline on conductive glass by Zhang et al. [25]. Increasing in the number of deposition cycles results in darker polymer film as was visually observed in optical image, Figure 3(f). This means that more PPy was being coated onto the conductive glass (i.e., thicker polymer films as summarized in Table 1). The morphology of PPy films was characterized by SEM and is shown in Figures 3(a)-3(c). It was observed that PPy forms nanoparticle-like structures with particle sizes of $\sim 90-120 \mathrm{~nm}$ for all three cycles. Films with longer deposition times seem to have rougher surfaces. Hence, the nanostructure-like and rough polymer surfaces should facilitate better dye-sensitized solar cell performance. This is because there is larger interface area between electrodes and electrolyte promoting the $\mathrm{I}_{3}{ }^{-}$reduction rate and the shortcircuit current density, as predicted in (1).

PPy films can be used as DSSC counter electrodes if they exhibit a good redox activity with $\mathrm{I}^{-} / \mathrm{I}_{3}{ }^{-}$. To analyze the catalytic activity of PPy films, cyclic voltammogram (CV) was conducted in $10 \mathrm{mM} \mathrm{LiI}, 1 \mathrm{mM} \mathrm{I}_{2}$, and $0.1 \mathrm{M} \mathrm{LiClO}_{4}$ in acetonitrile solution at a scan rate of $20 \mathrm{mV} / \mathrm{s}$. Figure 4 shows the CV curves of PPy and Pt films. Pt film has two oxidation peaks $(\sim 0.4$ and $\sim 0.7 \mathrm{~V})$ and two reduction peaks $(\sim 0.5$ and $\sim-0.1 \mathrm{~V})$. PPy films also generate two oxidation peaks $(\sim 0.4$ and $\sim 0.8 \mathrm{~V})$ and two reduction peaks $(\sim 0.4$ and $\sim-0.12 \mathrm{~V})$. The presence of oxidation and reduction peaks confirms that PPy films can be used as DSSC counter electrodes. It was observed that oxidation and reduction voltages of PPy films are higher than those of Pt film. This may be due to low polymer conductivities, which is similar to the observations in the work of Wu et al. [22].

3.2. DSSC Performance. The performance of DSSCs was measured under light irradiation of $100 \mathrm{~mW} / \mathrm{cm}^{2}$. Photocurrent density $(J)$-photovoltage versus $(V)$ curves are presented in Figure 5. Photoelectric parameters such as short-circuit current density $\left(J_{\mathrm{sc}}\right)$, open-circuit voltage $\left(V_{\mathrm{oc}}\right)$, fill factor $(\mathrm{FF})$, and energy conversion efficiency $(\eta)$ are extracted from $J-V$ curves and are given in Table 1. It was observed that Pt DSSC has a higher energy conversion efficiency $(\sim 7.59 \%)$ than all PPy DSSCs. Surprisingly, the efficiency of PPy cells is found to decrease with the number of deposition cycles (or polymer thickness) even though the thicker films have the rougher surfaces. In addition, the $J-V$ curves of PPy DSSCs exhibit less squareness and lower FF values than Pt DSSC. The curve squareness and FF are primarily governed by the solar cell impedance, that is, charge-transfer resistance at the working electrode/electrolyte, charge-transfer resistance at the counter electrode/electrolyte, Nernst diffusion, and series resistance.

To verify the change of DSSC impedances, electrochemical impedance spectroscopy (EIS) was conducted, and Nyquist curves are plotted in Figure 6. It can be seen from this figure that the impedance of Pt solar cell ( $\sim 37 \Omega$ estimated from Nyquist curve) is much smaller than that of PPy solar cells $(\sim 170-400 \Omega)$. This means that Pt cell has a lower charge-transfer resistance than polymer cells. Small charge-transfer resistance allows for more rapid electron transport and better solar cell performance. Large charge-transfer resistance will depress electron transport resulting in poor solar cell performance. It is noted that these DSSC devices are constructed of the same FTO glass, $\mathrm{TiO}_{2}$ films, and electrolyte. Thus, the charge-transfer resistance at working electrode/electrolyte, Nernst diffusion, and series resistance would be approximately the same. Therefore, the major influence on the different DSSC impedances is attributed to the different counter electrodes. It is seen from impedance spectra in Figure 6 that the increase in polymer thickness enlarges cell impedance. The increase of PPy DSSC impedances agrees well with the reduction of cell efficiencies as listed in Table 1. The inset of Figure 6 reveals that Pt DSSC impedance is demonstrated by two semicircles. The high-frequency semicircle presents the charge-transfer resistance at the counter electrode/electrolyte interface. The low-frequency semicircle indicates the charge-transfer resistance at the working electrode/electrolyte interface. However, there are no two distinct semicircles visible in all polymer cases. This is because the charge-transfer resistance at polymer/electrolyte is very large (higher than Pt cell about an order of magnitude) overlaid on the charge-transfer resistance at the working electrode/electrolyte interface curve that is, low-frequency semicircle is hidden in the chargetransfer resistance at the polymer/electrolyte interface. The undistinguished PPy impedance phenomenon was also observed by Makris et al. [24].

For a comparison to alternating current deposition, PPy films were also prepared by direct current (DC) deposition at an electrical potential of $0.8 \mathrm{~V}$ for two durations (4 $\mathrm{s}$ and $8 \mathrm{~s}$ ). Potential of $0.8 \mathrm{~V}$ was used to prepare PPy film because it was observed in AC deposition curves (Figure 1(a)) that polymer is significantly forming on the FTO surface at $0.8 \mathrm{~V}$. Figure 1(b) shows that the deposition current of the 8-s film exhibits a declining trend. Decreasing current implies reduction of PPy polymerization on conductive glass. This may be caused by the increase of the film resistance minimizing electrons transferring from the electrodes to monomers. SEM images of the direct current PPy films (Figures 3(d)$3(\mathrm{e}))$ also show nanoparticle-like structures $(\sim 100-125 \mathrm{~nm})$ as observed in AC-PPy films. The $J-V$ curves (in Figure 5) of the DC-PPy cells also deviate in their squareness as well as having low FF and efficiency values. The low performance of the DC polymer cells is due to large impedance values, 


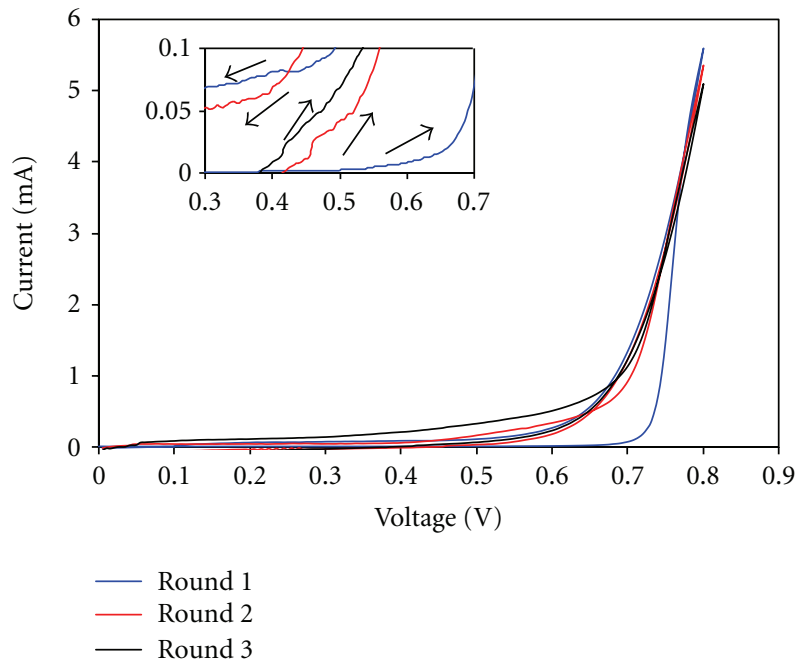

(a)

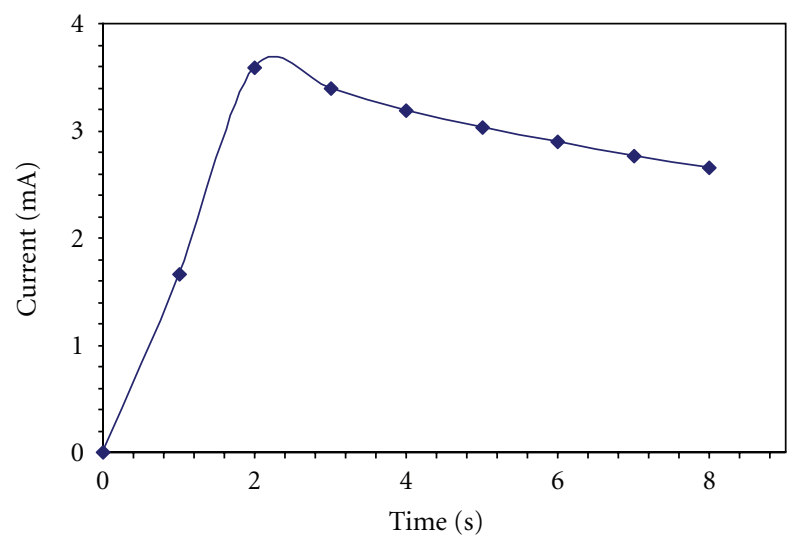

(b)

FIGURe 1: (a) Plot of deposited current versus voltage of alternate current (AC) deposition of the 3-round PPy film (AC-3R-PPy); arrows in the inset indicate the direction of deposition voltage. (b) Plot of the deposited current versus time of direct current (DC) of 8-s PPy films (DC-8s-PPy).

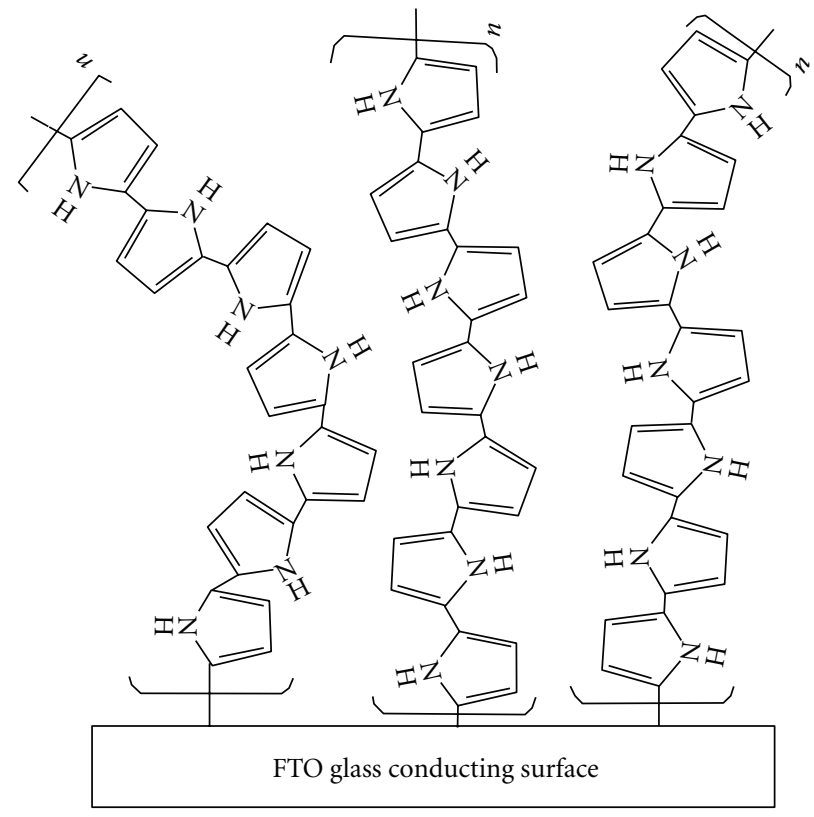

(a)

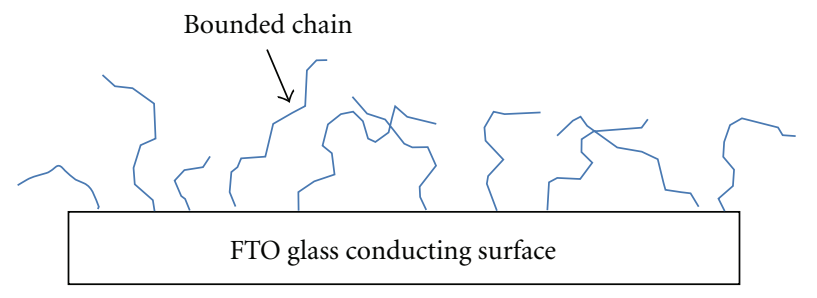

(b)

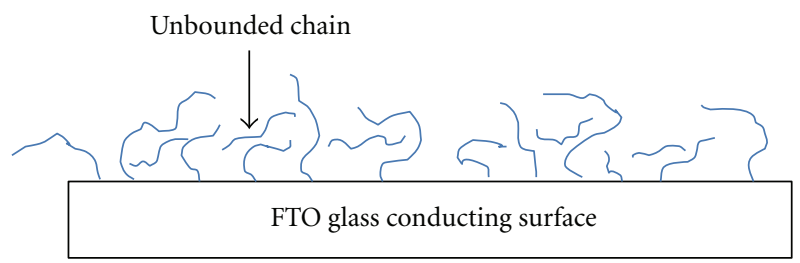

(c)

Figure 2: Schematic illustrating PPy formation on FTO glass, (a) PPy chemical structure, (b) PPy coated by AC method, and (c) PPy coated by DC method. 


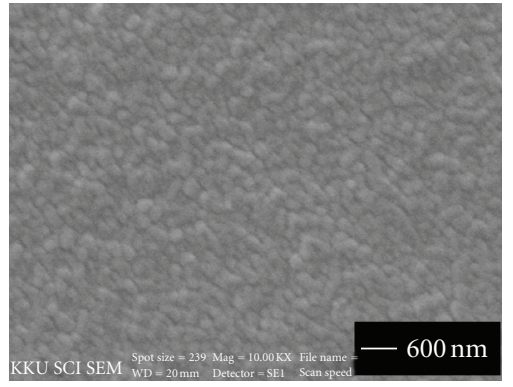

(a)

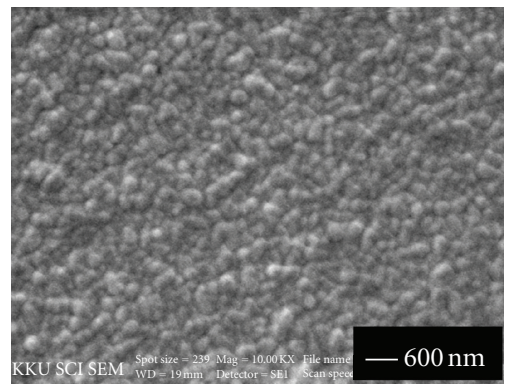

(d)

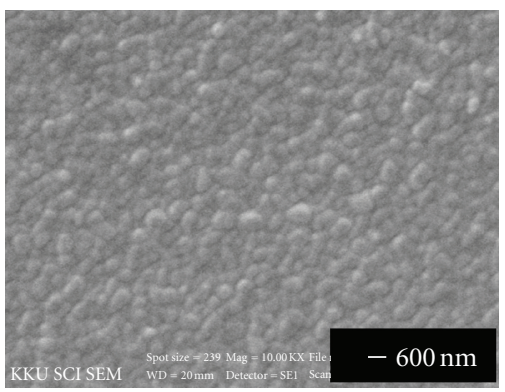

(b)

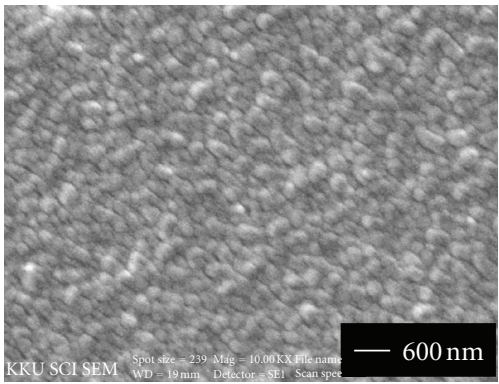

(e)

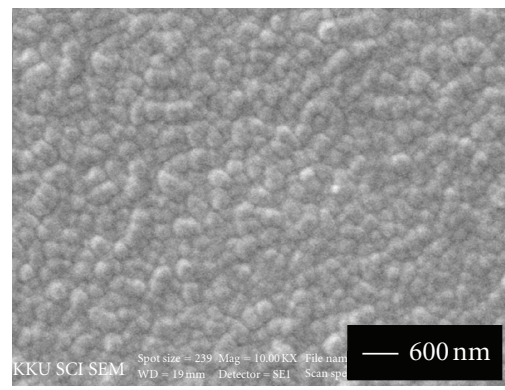

(c)

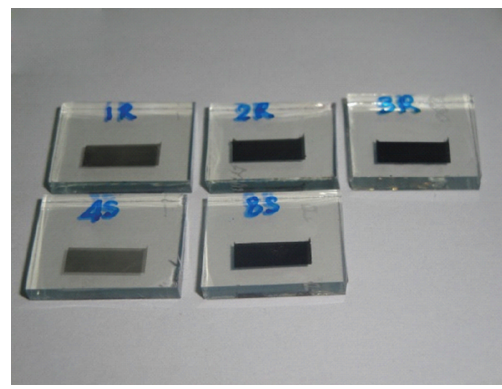

(f)

FIgure 3: Top views of PPy films deposited via (a) alternate current for 1 round $(A C-1 R-P P y)$, (b) alternate current for 2 rounds $(A C-2 R$ $P P y),(\mathrm{c})$ alternate current for 3 rounds $(A C-3 R-P P y)$, (d) direct current for $4 \mathrm{~s}(D C-4 s-P P y)$, (e) direct current for $8 \mathrm{~s}(D C-8 s-P P y)$, and (f) optical image of PPy films.

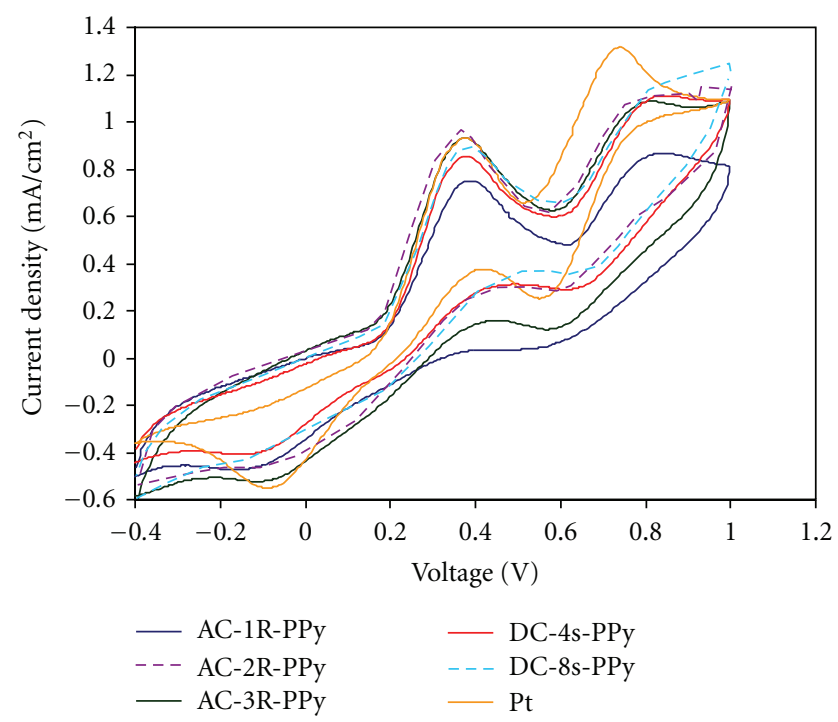

Figure 4: Cyclic voltammogram (CV) curves of PPy and Pt films at a scan rate of $20 \mathrm{mV} / \mathrm{s}$ in $10 \mathrm{mM} \mathrm{LiI}, 1 \mathrm{mM} \mathrm{I}_{2}$, and $0.1 \mathrm{M} \mathrm{LiClO}_{4}$ in acetonitrile solution.

as seen in the EIS spectra (Figure 6). Increasing deposition duration is also found to reduce solar cell performance and causes higher cell impedance similar to AC DSSCs.

Notice from Table 1 that the performance of AC DSSCs is higher than DC DSSCs. This can be explained by the difference of polymer thickness and growth rate. In case of AC deposition, polymer begins coating on conductive glass
TABLE 1: Summary of polymer film thickness, open-circuit voltage $\left(V_{\text {oc }}\right)$, short-circuit current density $\left(J_{\text {sc }}\right)$, fill factor $(\mathrm{FF})$, solar cell efficiency $(\eta)$ of the Pt and PPy DSSCs.

\begin{tabular}{lccccc}
\hline DSSC & Thickness $(\mu m)$ & $J_{\text {sc }}\left(\mathrm{mA} \cdot \mathrm{cm}^{-2}\right)$ & $V_{\text {oc }}(\mathrm{V})$ & FF & $\eta(\%)$ \\
\hline$A C-1 R-P P y$ & 0.30 & 14.58 & 0.74 & 0.43 & 4.72 \\
$A C-2 R-P P y$ & 1.20 & 16.04 & 0.77 & 0.32 & 4.07 \\
$A C-3 R-P P y$ & 2.04 & 14.62 & 0.74 & 0.29 & 3.25 \\
$D C-4 s-P P y$ & 0.27 & 13.92 & 0.74 & 0.38 & 4.02 \\
$D C-8 s-P P y$ & 5.63 & 15.12 & 0.73 & 0.30 & 3.36 \\
$\mathrm{Pt}$ & $\mathrm{N} / \mathrm{A}$ & 14.63 & 0.73 & 0.70 & 7.59 \\
\hline
\end{tabular}

at $\sim 0.6 \mathrm{~V}$ in the first cycle and at $\sim 0.4 \mathrm{~V}$ in subsequent cycles, as seen in Figure 1(a). This results in a discontinuity in PPy deposition and a low deposition rate. Alternatively when considering the DC method, polymer is continually coated for the entire deposition period leading to the faster growth rate and the thick film. However, we had observed that a lot of polymerwere washed of DC-PPy films during film rinsing. This is explained by the higher deposition rate of DC method inducing some unbounded PPy chains forming on DC films, but not existing on AC films as illustrated in Figures 2(b)-2(c). The unbounded chains may prevent electrons transferring between bonded PPy chains and $\mathrm{I}_{3}{ }^{-}$leading to poor DC-PPy film conductivity. It is observed in Figure 6 that the impedance of DC-4s-PPy DSSC $(\sim 350 \Omega)$ is larger than that of $A C-1 R-P P y$ DSSC $(\sim 170 \Omega)$. Hence, the presence 


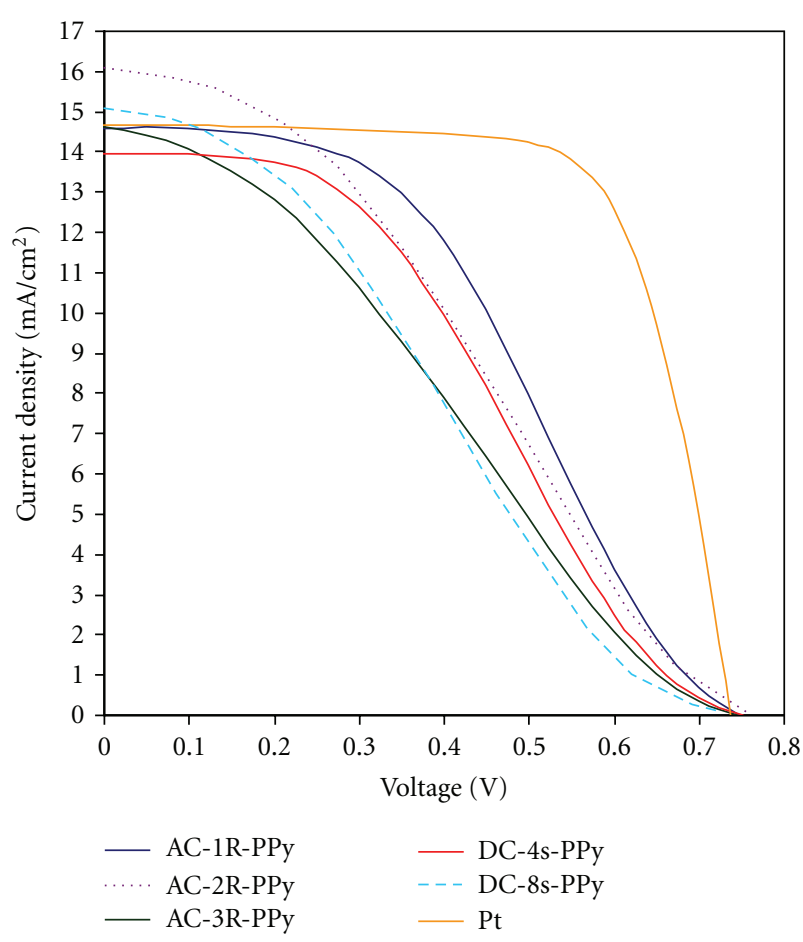

Figure 5: Photocurrent density $(J)$ versus. photovoltage $(V)$ curves of PPy and Pt DSSCs.

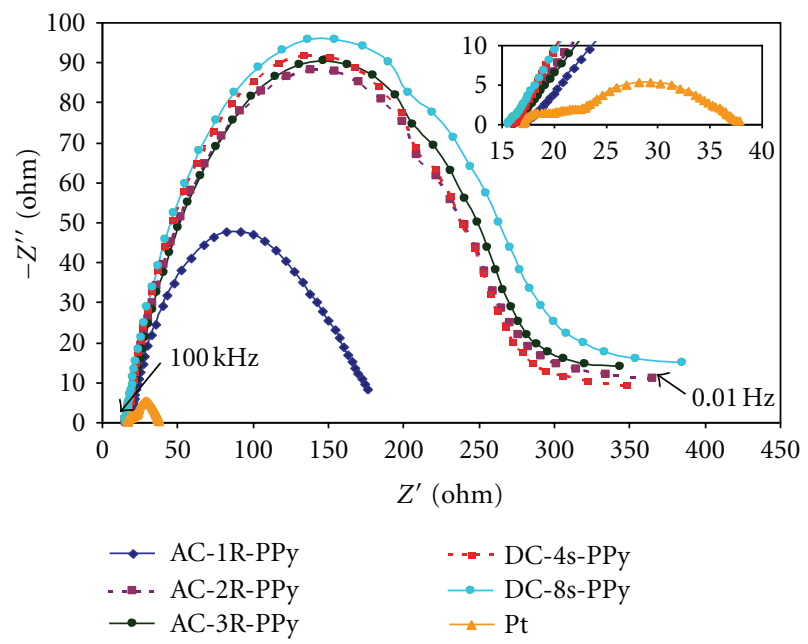

FIgUre 6: Nyquist plots of Pt and PPy DSSCs.

of unbounded chains is an explanation to the thinner $D C-4 s-$ $P P y$ film having lower solar cell efficiency than that of $A C$ $1 R$-PPy DSSC. In addition, grain size of AC-PPy films seems to be smaller than that seen in DC-PPy films as observed in Figure 3. The small grain size will increase the interfacial area between polymer surface and electrolyte. These two phenomena (unbounded chain and larger grain size) are possible factors responsible for low DC DSSC efficiency. Thus, it can be inferred that the thin and bounded PPy film is preferable for high dye-sensitized solar cell performance. Notice that PPy DSSCs (both AC and DC cells) of the current study show poorer performance than reported in $\mathrm{Wu}$ et al. [22] and Jeon et al. [23]. This should be attributed to different PPy structures, sizes, and film thickness in the three studies. Wu et al. [22] and Jeon et al. [23] used smallersized nanoparticle polypyrrole $(\sim 40-60 \mathrm{~nm}$ for $\mathrm{Wu}$ et al. and $\sim 85 \mathrm{~nm}$ for Jeon et al.) in coating the polymer films. The result is larger interfacial area and higher film porosity than direct polymerization on conductive glass done in the current study. Sharma et al. [18] used the ultrashort-pulse electrochemical deposition method to deposit PPy thin films. They obtained the short polymer chain length and high degree of polymer conjugation, which exhibited the high redox transition and high specific capacitance. Thus, the short-pulse electrochemical deposition is one of possible approaches in improving electrochemically deposited PPy film catalytic activity and PPy-based dye-sensitized solar cell performance.

\section{Conclusions}

PPy films were successfully prepared by electrochemical deposition (both alternative current and direct current) on conductive glass and used as DSSC counter electrodes. Scanning electron microscopy showed that PPy forms nanoparticle-like structures with particle sizes $\sim 90-125 \mathrm{~nm}$. The highest energy conversion efficiency of PPy DSSCs in this study was $\sim 4.72 \%$. The performance of PPy DSSCs decreases with PPy thickness. This is attributed to increase in charge-transfer resistance at the PPy surface/electrolyte for both the alternating and direct current depositions. DC DSSCs deliver lower efficiency than AC DSSCs because of the formation of unbounded PPy chains on polymer films.

\section{Acknowledgments}

This work was supported by the Higher Education Research Promotion and National Research University Project of Thailand, Office of the Higher Education Commission, through the advanced functional materials cluster of Khon Kaen University, The Thailand Research Fund and Khon Kaen University (TRF, MRG5480024), Integrated Nanotechnology Research Center, Khon Kaen University, and The Center of Excellence in Physics (ThEP).

\section{References}

[1] B. O’Regan and M. Grätzel, "A low-cost, high-efficiency solar cell based on dye-sensitized colloidal $\mathrm{TiO}_{2}$ films," Nature, vol. 353, no. 6346, pp. 737-740, 1991.

[2] A. Kay and M. Grätzel, "Low cost photovoltaic modules based on dye sensitized nanocrystalline titanium dioxide and carbon powder," Solar Energy Materials and Solar Cells, vol. 44, no. 1, pp. 99-117, 1996.

[3] N. Papageorgiou, Y. Athanassov, M. Armand et al., "The performance and stability of ambient temperature molten salts for solar cell applications," Journal of the Electrochemical Society, vol. 143, no. 10, pp. 3099-3108, 1996.

[4] N. Papageorgiou, W. F. Maier, and M. Grätzel, "An iodine/ triiodide reduction electrocatalyst for aqueous and organic 
media," Journal of the Electrochemical Society, vol. 144, no. 3, pp. 876-884, 1997.

[5] Y. Nishikitani, T. Kubo, and T. Asano, "Modeling of photocurrent in dye-sensitized solar cells fabricated with PVDF-HFPbased gel-type polymeric solid electrolyte," Comptes Rendus Chimie, vol. 9, no. 5-6, pp. 631-638, 2006.

[6] T. N. Murakami, S. Ito, Q. Wang et al., "Highly efficient dyesensitized solar cells based on carbon black counter electrodes," Journal of the Electrochemical Society, vol. 153, no. 12, pp. A2255-A2261, 2006.

[7] K. Suzuki, M. Yamaguchi, M. Kumagai, and S. Yanagida, "Application of carbon nanotubes to counter electrodes of dye-sensitized solar cells," Chemistry Letters, vol. 32, no. 1, pp. 28-29, 2003.

[8] Y. Saito, T. Kitamura, Y. Wada, and S. Yanagida, "Application of poly(3,4-ethylenedioxythiophene) to counter electrode in dye-sensitized solar cells," Chemistry Letters, no. 10, pp. 10601061, 2002.

[9] M. Biancardo, K. West, and F. C. Krebs, "Quasi-solid-state dyesensitized solar cells: Pt and PEDOT:PSS counter electrodes applied to gel electrolyte assemblies," Journal of Photochemistry and Photobiology A, vol. 187, no. 2-3, pp. 395-401, 2007.

[10] Y. Saito, W. Kubo, T. Kitamura, Y. Wada, and S. Yanagida, " $\mathrm{I}^{-} / \mathrm{I}_{3}{ }^{-}$redox reaction behavior on poly (3,4-ethylenedioxythiophene) counter electrode in dye-sensitized solar cells," Journal of Photochemistry and Photobiology A, vol. 164, no. 13, pp. 153-157, 2004.

[11] Y. Saito, T. Kitamura, Y. Wada, and S. Yanagida, "Application of poly(3,4-ethylenedioxythiophene) to counter electrode in dye-sensitized solar cells," Chemistry Letters, no. 10, pp. 10601061, 2002.

[12] T. Yohannes and O. Inganäs, "All-solid-state photoelectrochemical energy conversion with the conjugated polymer poly[3-(4-octylphenyl)-2,2' -bithiophene]," Synthetic Metals, vol. 107, no. 2, pp. 97-105, 1999.

[13] T. C. Wei, C. C. Wan, and Y. Y. Wang, "Poly ( $N$-vinyl-2pyrrolidone)-capped platinum nanoclusters on indium-tin oxide glass as counterelectrode for dye-sensitized solar cells," Applied Physics Letters, vol. 88, no. 10, Article ID 103122, 3 pages, 2006.

[14] L. X. Wang, X. G. Li, and Y. L. Yang, "Preparation, properties and applications of polypyrroles," Reactive and Functional Polymers, vol. 47, no. 2, pp. 125-139, 2001.

[15] S. Mokrane, L. Makhloufi, and N. Alonso-Vante, "Electrochemistry of platinum nanoparticles supported in polypyrrole (PPy)/C composite materials," Journal of Solid State Electrochemistry, vol. 12, no. 5, pp. 569-574, 2008.

[16] J. Wang, Y. Xu, X. Chen, and X. Du, "Electrochemical supercapacitor electrode material based on poly(3,4-ethylenedioxythiophene)/polypyrrole composite," Journal of Power Sources, vol. 163, no. 2, pp. 1120-1125, 2007.

[17] R. K. Sharma, A. C. Rastogi, and S. B. Desu, "Manganese oxide embedded polypyrrole nanocomposites for electrochemical supercapacitor," Electrochimica Acta, vol. 53, no. 26, pp. 7690 7695, 2008.

[18] R. K. Sharma, A. C. Rastogi, and S. B. Desu, "Pulse polymerized polypyrrole electrodes for high energy density electrochemical supercapacitor," Electrochemistry Communications, vol. 10, no. 2, pp. 268-272, 2008.

[19] B. H. Kim, D. H. Park, J. Joo, S. G. Yu, and S. H. Lee, "Synthesis, characteristics, and field emission of doped and de-doped polypyrrole, polyaniline, poly(3,4-ethylenedioxythiophene) nanotubes and nanowires," Synthetic Metals, vol. 150, no. 3, pp. 279-284, 2005.
[20] A. Joshi, S. A. Gangal, and S. K. Gupta, "Ammonia sensing properties of polypyrrole thin films at room temperature," Sensors and Actuators B, vol. 156, no. 2, pp. 938-942, 2011.

[21] D. Kopecký, M. Vrňata, F. Vysloužil et al., "Polypyrrole thin films for gas sensors prepared by matrix-assisted pulsed laser evaporation technology: effect of deposition parameters on material properties," Thin Solid Films, vol. 517, no. 6, pp. 2083-2087, 2009.

[22] J. Wu, Q. Li, L. Fan et al., "High-performance polypyrrole nanoparticles counter electrode for dye-sensitized solar cells," Journal of Power Sources, vol. 181, no. 1, pp. 172-176, 2008.

[23] S. S. Jeon, C. Kim, J. Ko, and S. S. Im, "Spherical polypyrrole nanoparticles as a highly efficient counter electrode for dyesensitized solar cells," Journal of Materials Chemistry, vol. 21, no. 22, pp. 8146-8151, 2011.

[24] T. Makris, V. Dracopoulos, T. Stergiopoulos, and P. Lianos, "A quasi solid-state dye-sensitized solar cell made of polypyrrole counter electrodes," Electrochimica Acta, vol. 56, no. 5, pp. 2004-2008, 2011.

[25] J. Zhang, T. Hreid, X. Li et al., "Nanostructured polyaniline counter electrode for dye-sensitised solar cells: fabrication and investigation of its electrochemical formation mechanism," Electrochimica Acta, vol. 55, no. 11, pp. 3664-3668, 2010. 


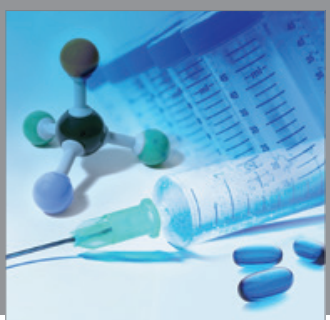

International Journal of

Medicinal Chemistry

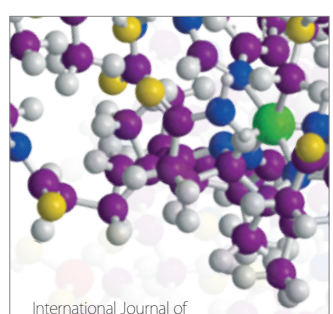

Carbohydrate Chemistry

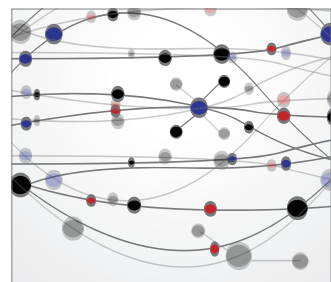

The Scientific World Journal
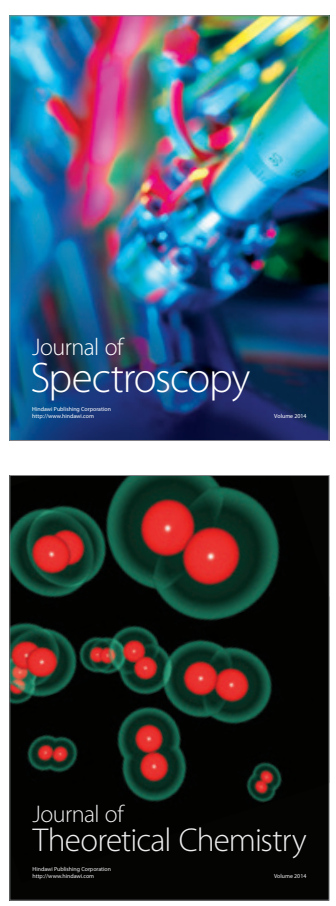
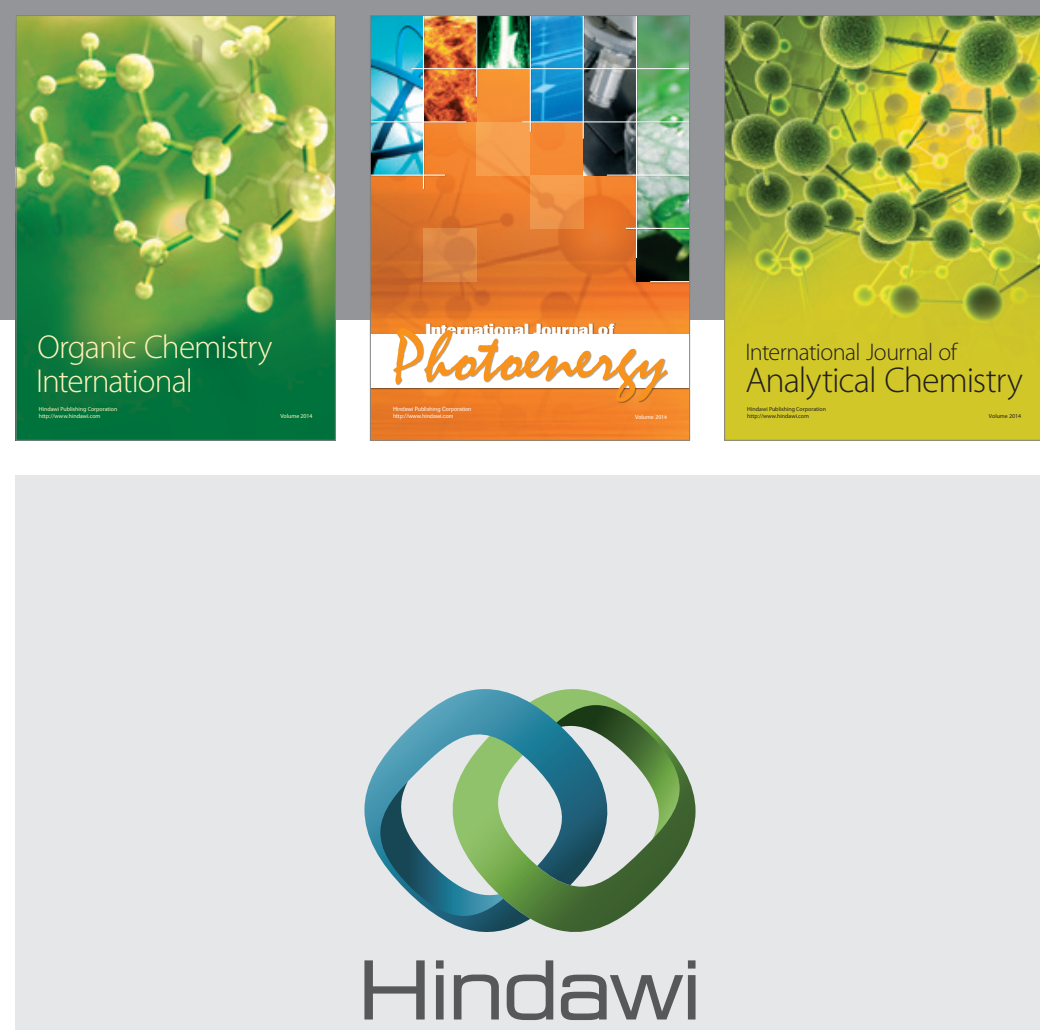

Submit your manuscripts at

http://www.hindawi.com
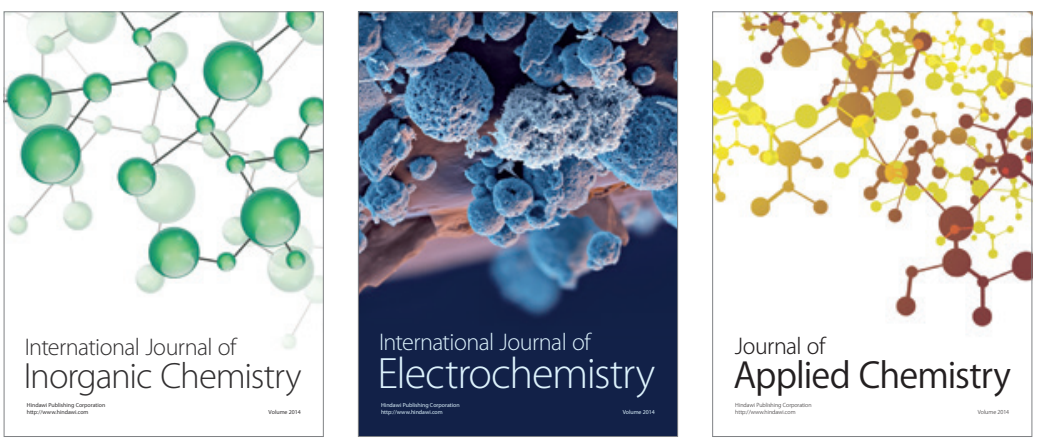

Journal of

Applied Chemistry
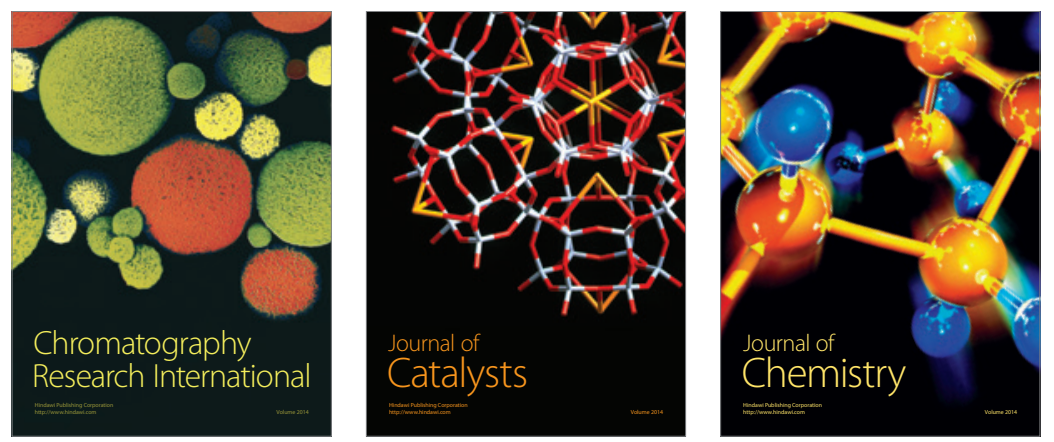
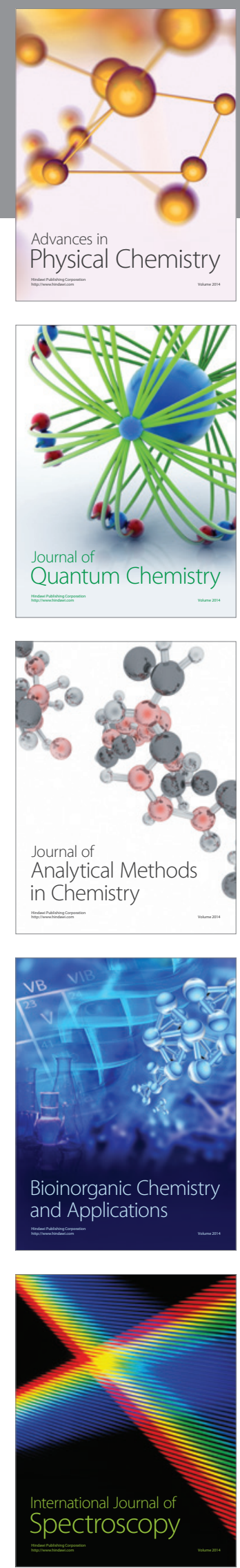